\title{
DETERMINATION OF BURIED MAGNETIC MATERIAL'S GEOMETRIC DIMENSIONS
}

\author{
Yavuz Ege ${ }^{1}$, Adnan Kakilli ${ }^{2}$, Hakan Çıtak ${ }^{3}$, Mustafa Çoramık ${ }^{1}$ \\ ${ }^{1}$ Necatibey Education Faculty and the Department of Physics, \\ Balıkesir University, Balıkesir 10100, Turkey \\ ${ }^{2}$ Department of Electrical Education, Technical Education Faculty, \\ Marmara University, Istanbul 34722, Turkey \\ ${ }^{3}$ Balıkesir Vocational High School, Electric Program, \\ Balıkesir University, Balıkesir 10145, Turkey
}

\begin{abstract}
It is important to find buried magnetic material's geometric features that are parallel to the soil surface in order to determine anti-tank and anti-personnel mine compatible to standards. So that it is possible to decrease the number of false alarms by separating the samples that have got non-standard geometries. For this purpose, in this study the anomalies occurred at horizontal component of the earth's magnetic field by buried samples are determined with magnetic sensor. In the study, KMZ51 AMR is used as the magnetic sensor. The position-controlled movement of the sensor along $x$-y axis is provided with $2 D$ scanning system. Trigger values of sensor output are evaluated with respect to the scanning field. The experiments are redone for the samples at different geometries and variables are defined for geometric analysis. The experimental conclusions obtained from this paper will be discussed in detail.
\end{abstract}

\section{KEYWORDS}

Magnetic material, Magnetic sensor, Magnetic anomaly, Landmine.

\section{INTRODUCTION}

In our day, metal detectors are commonly used for removing the military land mines. Metal detectors are electronic devices that are designed for finding mineral deposits under the ground, metal ware or land mines [1-3]. These devices are working in accordance with the procedures of electromagnetic induction method. In the device, there are primary and secondary (search) bobbins.

When a magnetic field that has got changeable intensity is formed with the primary bobbin in an environment in which there is a conducting subject, electric field is induced on the conductive object and this field causes a load flow in the conductive object. The flow that is induced because of this load flow produces a secondary weak magnetic field that has got changeable intensity. On the other hand, the secondary magnetic field produces an induction flow on secondary bobbin. When the induced flow occurred on secondary bobbin is examined on a wideband (30 Hz- 24 $\mathrm{kHz}$ ), a signal which can identify the object specifically is obtained (Fig.1).

The choice of flow's frequency that will be applied to primary bobbin on determined object is identified with this Formula; [4,5]

DOI : $10.5121 /$ sipij.2016.7502 


$$
\mathrm{f}=2500 \times \frac{\mathrm{R}}{\mu_{\mathrm{r}} \cdot \mathrm{d}^{2}}
$$

Here, $\mu_{\mathrm{r}}$ shows depth in kind d inch, (T.m/A) shows relative magnetic permeability of the object, and $\mathrm{R}$ shows electrical resistance $(\Omega)$ of the object.

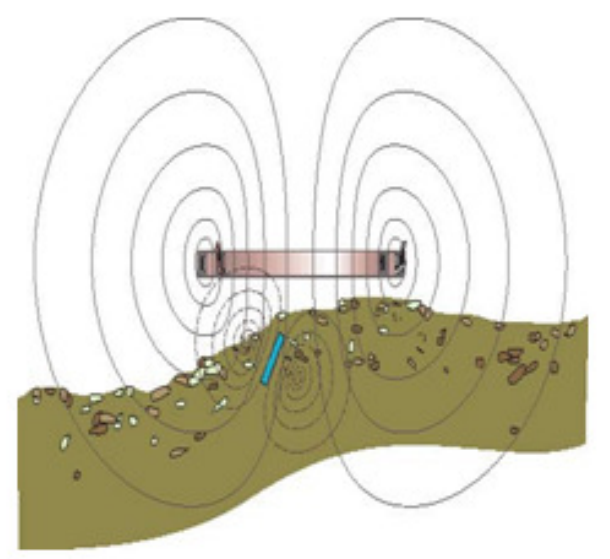

Figure 1. Application of Electromagnetic Induction Method

In electromagnetic induction method, while its vertically depth range $(12 \mathrm{~cm})$ is sufficient, its ability in recognizing a metal from another metal or perceiving the objects that have got underperformed metal range subjects is really low [6].That is why these detectors' false target numbers are more than real targets [6,7].This high false alarm rate lowers mine spotting speed and also it makes the method expensive and dangerous [8]. Recently, the false alarms which are raised from small metal wastes such as shell casing, shrapnel have been decreased by using GPR sensor with secondary bobbin. However, the cost of these double sensor metal detectors is higher than the others.

In literature, some studies have been developed such as separating metal mine cases confirming to standards from magnetic samples that have got nonstandard geometry by finding buried magnetic materials' geometrical features parallel to the soil surface in order to decrease the false alarms number [9-10].Therefore, with the aim of decreasing the number of false alarms, it is tried to identify and classify buried magnetic materials' geometrical features parallel to the soil surface by using magnetic anomaly method in this study.

The anomalies formed by the earth at the horizontal component of magnetic field in buried samples' scanning field are determined with KMZ51 AMR magnetic sensor. Sensor output voltage changes are evaluated according to the scanning field. The experiments are repeated for the samples at different geometries and variables for geometrical analysis are determined. The other parts of this paper, the experimental results are discussed in detail.

\section{MATERIAL AND METHOD}

In the study, a new magnetic measurement system that uses magnetic anomaly technique, determines buried magnetic materials' upper surface views and decides whether they are standard or nonstandard and classifies them is developed. Developed magnetic measurement system consists of two parts as; 2D sweeping system and electronic unit (Fig. 2). 
Signal \& Image Processing : An International Journal (SIPIJ) Vol.7, No.5, October 2016

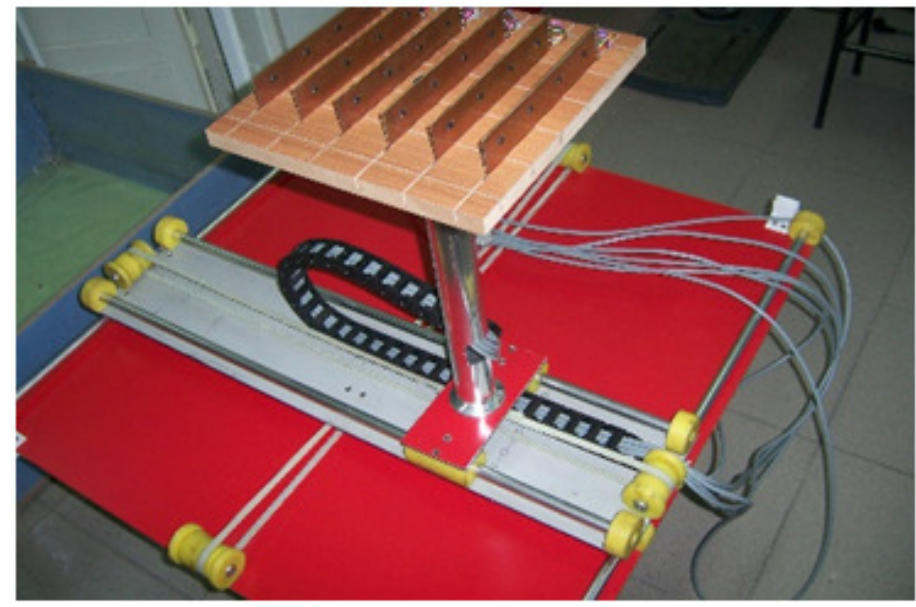

(a)

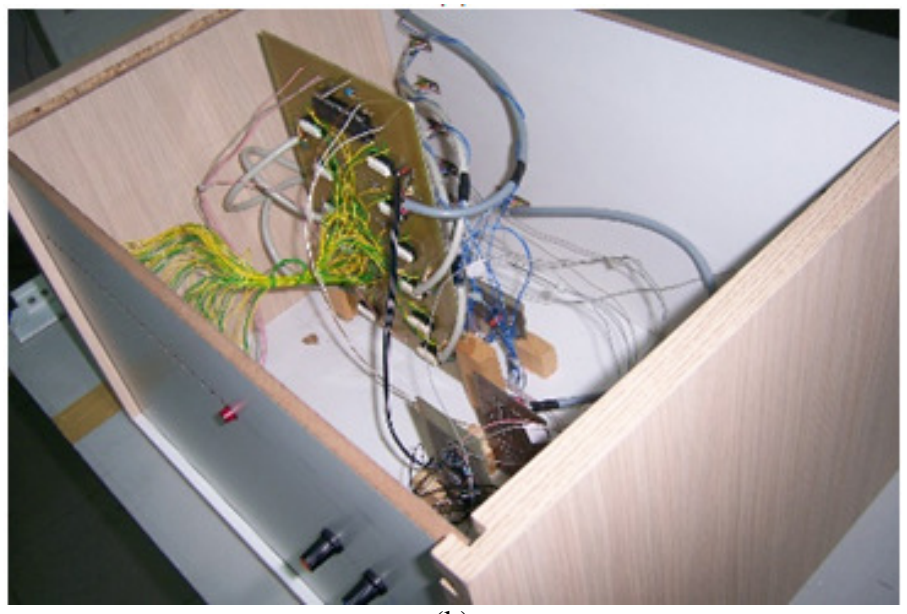

(b)

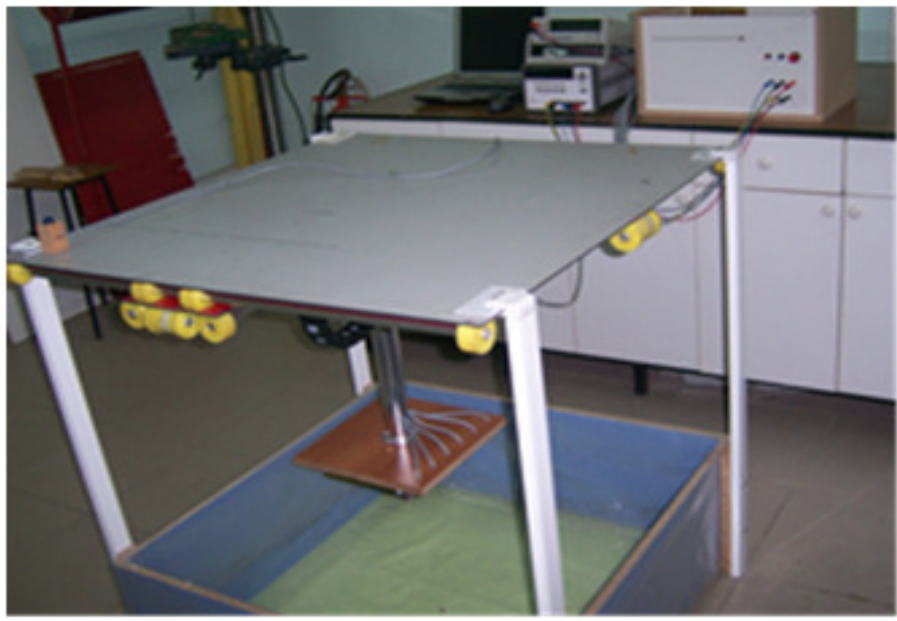

(c)

Figure 2. a) The view of 2D scanning system, b) The view of electronic unit, c) The whole view of magnetic measurement system 
In the study, the soil which consists of $\% 4.88 \mathrm{Fe}_{2} \mathrm{O}_{3}$ that is obtained by using X-Ray diffraction device (XRD) according to mineralogical analysis, is put into the soil reservoir of the system. In addition, 1030 and 1040 serial magnetic materials, which are produced at AISI (American Iron and Steel Institution) standards and used for making military metal covered mines, are used as the test sample. The test samples have got cylindrical and prismatic geometry. The names are given to test samples in order to distinguish them from each other. Among them, Sample 1, Sample 16, Sample 19 and Sample 22 are cylindrical samples with different height and diameter. In the study, first of all, these selected cylindrical samples are buried right under the soil into the center of scanning field. Later, magnetic anomalies occurred by samples in the magnetic field of the earth, with moving sensors at $1 \mathrm{~cm}$ intervals in scanning field, are determined with sensor voltage changes. Lastly, sensor voltage changes that are obtained according to the scanning field are converted into gray-scale graph (Fig.3).

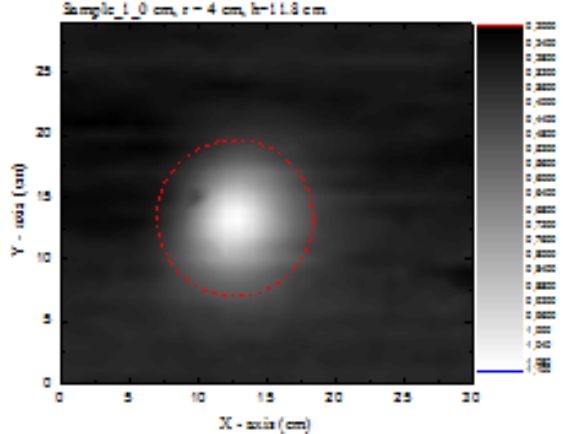

(a)

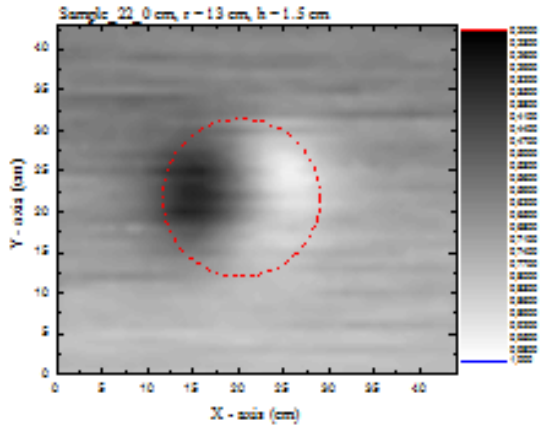

(c)

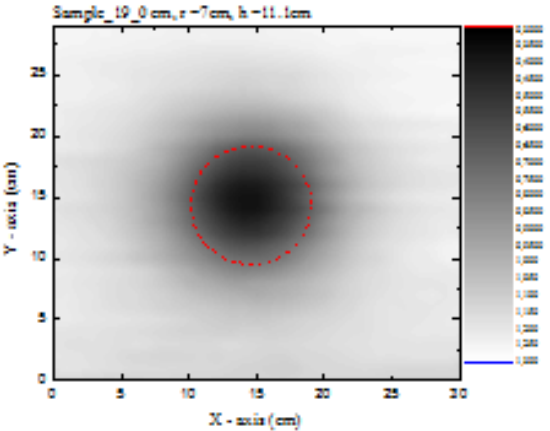

(b)

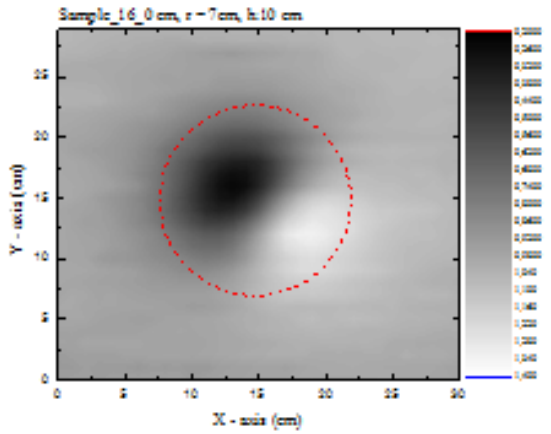

(d)

Figure 3. Selected cylindrical samples' sensor voltage changes obtained according to the scanning field.

Fig.3a gray scale graph belongs to Sample 1 and Fig.3b gray scale graph belongs to Sample 19. Both of these cylindrical samples' diameters are prominently smaller than their height. When the graphs of both samples are compared, it can be seen that the graphs have got the same characteristics. Fig.3c gray scale graph belongs to Sample 22 and Fig.3d gray scale graph belongs to Sample 16. While diameter is very bigger than height at Sample 22, height is bigger than diameter but its size is closer to the diameter's size. However it can be said that the graphs of two samples have got same characteristics. In that case, it can be commented about diameter- height relation with the gray- scale graphs of sensor voltage changes obtained according to the scanning field and geometrical structures of the samples. In the study, change graphs of sensor output triggers for $\mathrm{x}$ axis are fitted in order to find diameter information of cylindrical samples, mathematical catenary conforming to this characteristic change is determined and the equation of this catenary is found (Fig.4). 
Signal \& Image Processing : An International Journal (SIPIJ) Vol.7, No.5, October 2016

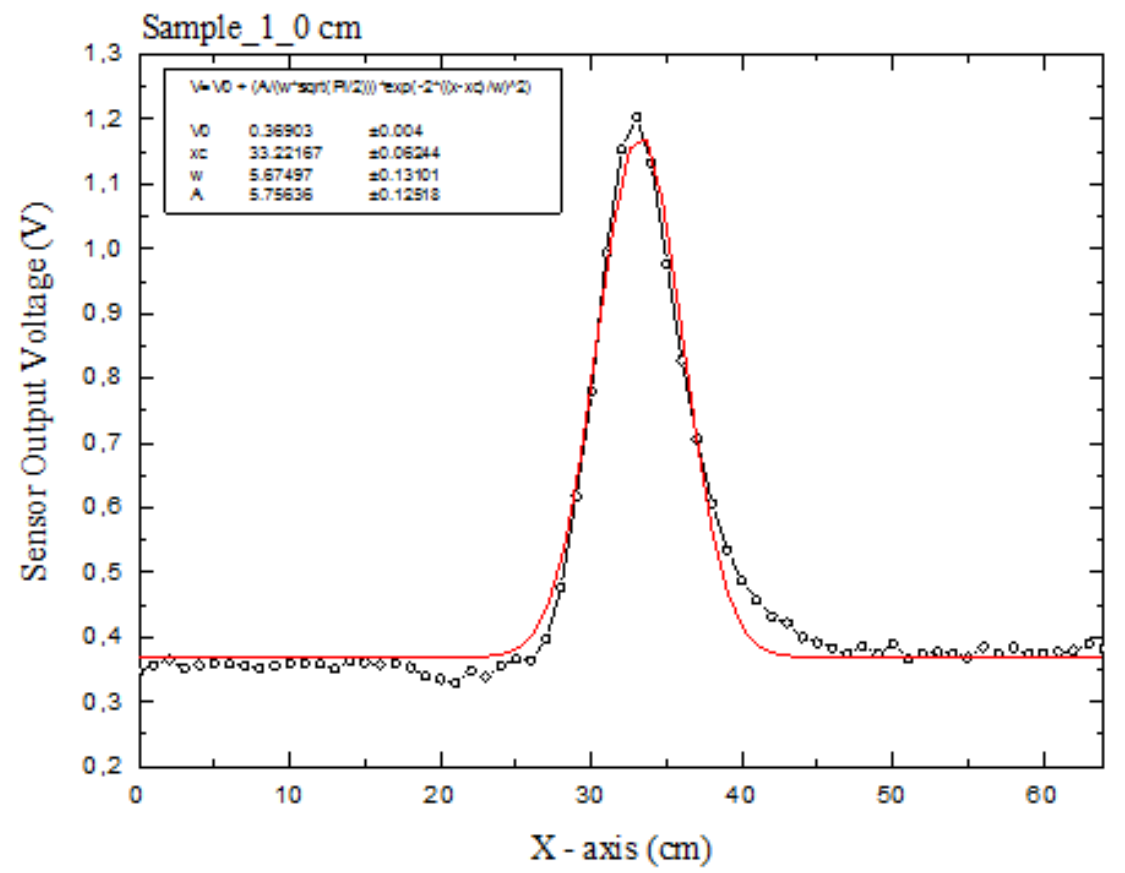

(a)

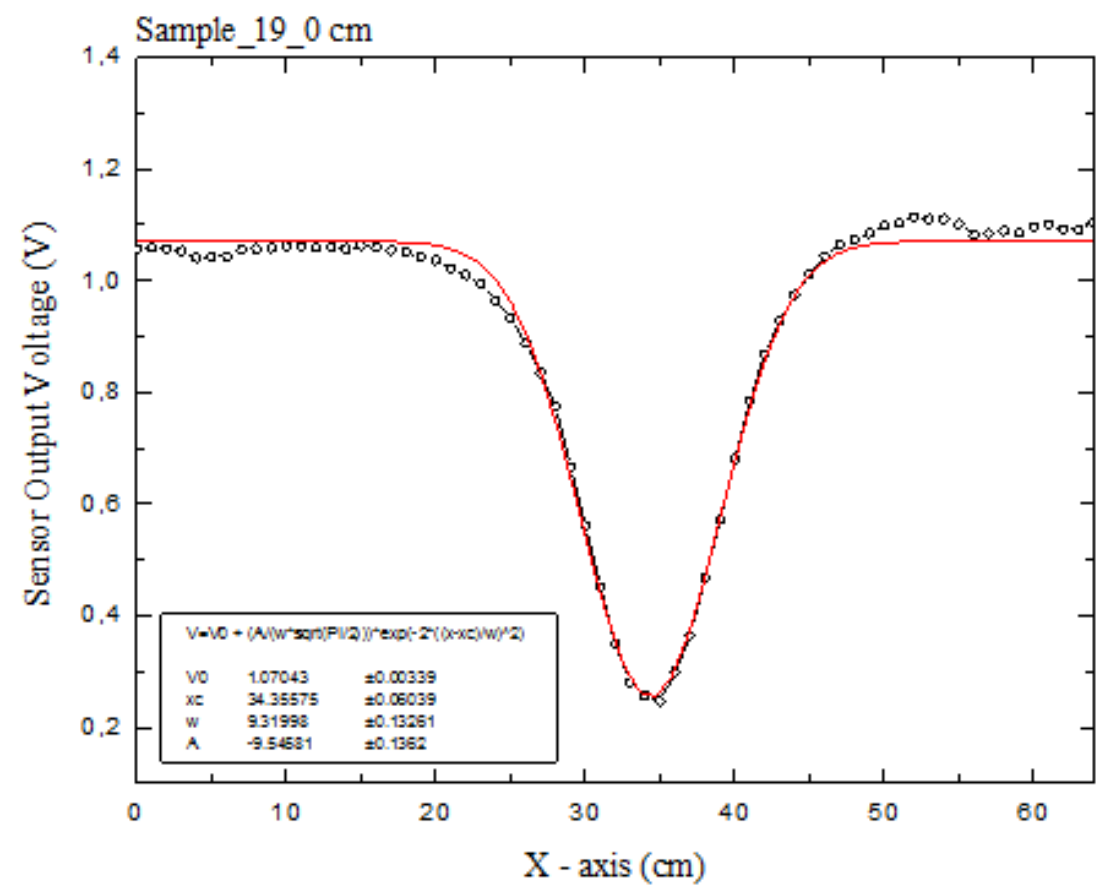

(b) 
Signal \& Image Processing : An International Journal (SIPIJ) Vol.7, No.5, October 2016

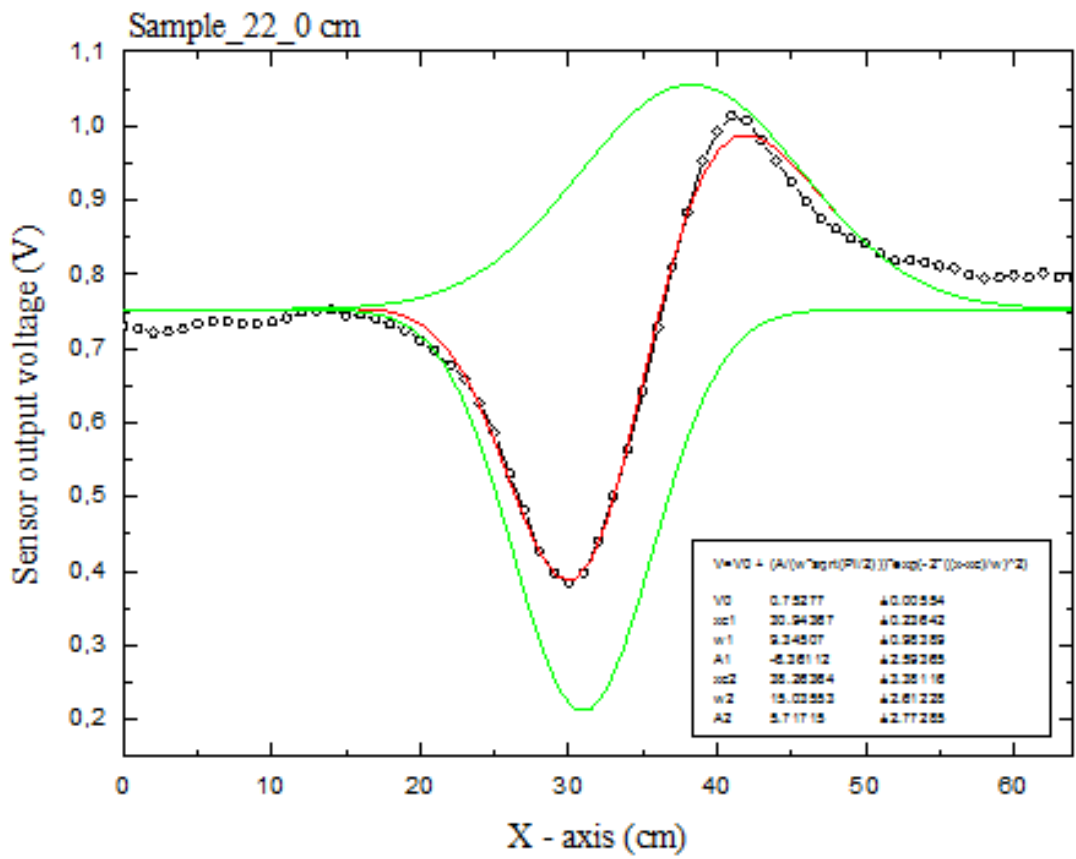

(c)

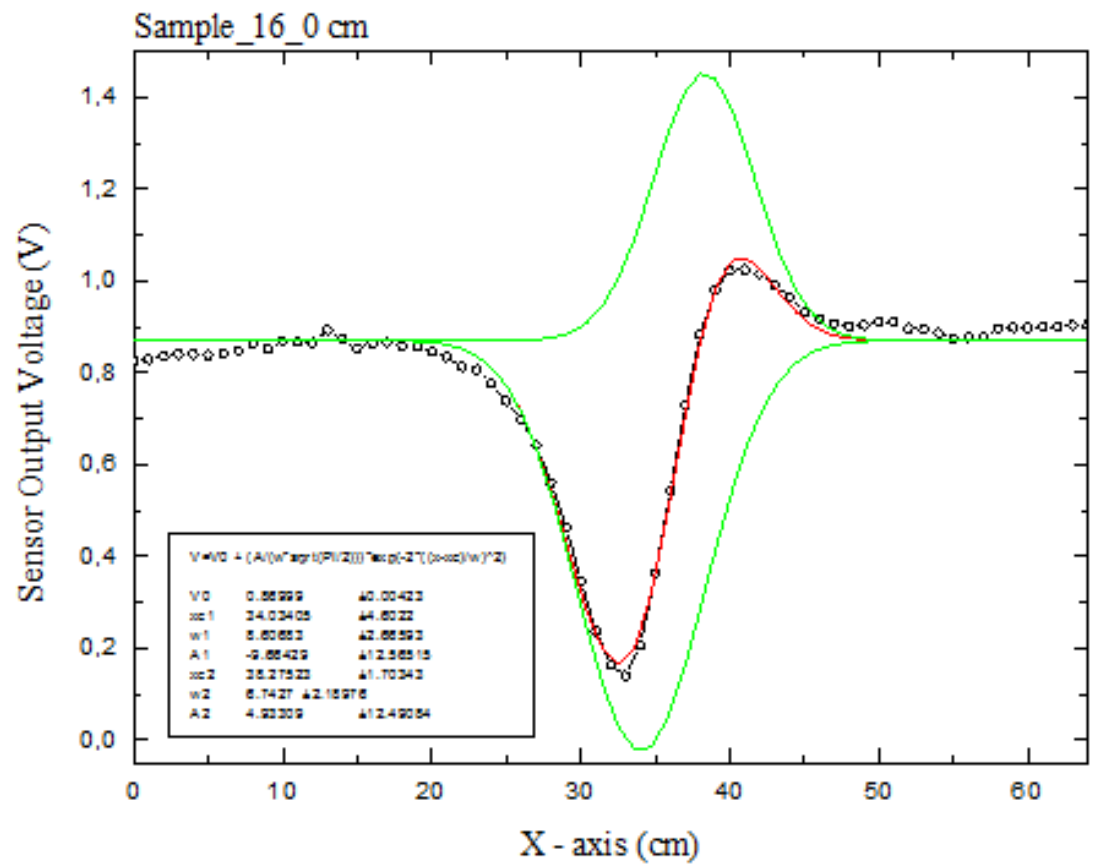

(d)

Figure 4. For cylindrical samples, fitting changes of sensor output triggers according to $\mathrm{x}$ axis

The equation of mathematical catenary obtained for cylindrical samples is like in Eq.2. However, as it is seen at Fig.4c and Fig.4d, at cylindrical samples whose diameter and height can be compared, the super position of two gaussian curves give the equation of mathematical catenary (Eq.3). 
Signal \& Image Processing : An International Journal (SIPIJ) Vol.7, No.5, October 2016

$$
\begin{gathered}
\mathrm{V}_{\text {Output }}=\mathrm{V}_{0}+\frac{\mathrm{A}}{\mathrm{W} \cdot \sqrt{\frac{\pi}{2}}} \cdot \mathrm{e}^{\left.-2\left(\mathrm{X}-\mathrm{X}_{\mathrm{C}}\right) / \mathrm{W}\right)^{2}} \\
\mathrm{~V}_{\text {Output }}=\mathrm{V}_{0}+\frac{\mathrm{A}_{1}}{\mathrm{~W}_{1} \cdot \sqrt{\frac{\pi}{2}}} \cdot \mathrm{e}^{\left.-2\left(\mathrm{X}-\mathrm{X}_{\mathrm{Cl}}\right) / \mathrm{W}_{1}\right)^{2}}+\frac{\mathrm{A}_{2}}{\mathrm{~W}_{2} \cdot \sqrt{\frac{\pi}{2}}} \cdot \mathrm{e}^{\left.-2\left(\mathrm{X}-\mathrm{X}_{\mathrm{C} 2}\right) / \mathrm{W}_{2}\right)^{2}}
\end{gathered}
$$

At Eq.2; V0 presents voltage value read by sensor when there is no sample (Volt), $\mathrm{X}_{\mathrm{C}}$ presents the coordination of the point in which gaussian curve peaks at $\mathrm{x}$ axis $(\mathrm{cm}), \mathrm{W}$ presents gaussian curve's half height's width $(\mathrm{cm})$, A presents the field that is under the gaussian curve $\left(\mathrm{cm}^{2}\right)$.

With identifying all variants at fit equations formed for all cylindrical samples that have got the same magnetic permeability in which height is much bigger than diameter, the empirical formula that gives the approximate value of diameter is obtained as it is in Eq. 4.

$$
R \cong \frac{A}{(1.36)_{*}}
$$

Here, R presents “diameter" $(\mathrm{cm})$, A presents the field under the gaussian curve $\left(\mathrm{cm}^{2}\right),()^{*}$ presents the coefficient for the samples that have got stable magnetic permeability.

With identifying all variants at fit equations formed for all cylindrical samples in which diameter is bigger than or close to the diameter, the empirical formula that gives the approximate value of diameter is obtained as it is in Eq. 5.

$$
\mathrm{R} \cong \frac{\mathrm{W}_{1}+\mathrm{W}_{2}}{2}
$$

Here, $R$ presents diameter $(\mathrm{cm}), \mathrm{W}_{1}$ presents first gaussian curve's half height's width $(\mathrm{cm}), \mathrm{W}_{2}$ presents second gaussian curve's half height's width $(\mathrm{cm})$.

In the study, among test samples, from the prismatic ones, Sample 46 and Sample 54 are chosen. The upper surface of Sample 46 is rectangular and Sample 54's upper surface is square. First of all, these prismatic samples are buried right under the soil one by one into the center of scanning field. Later, sensor voltage changes obtained according to scanning field are identified and they are converted into the gray-scale graph (Fig.5).

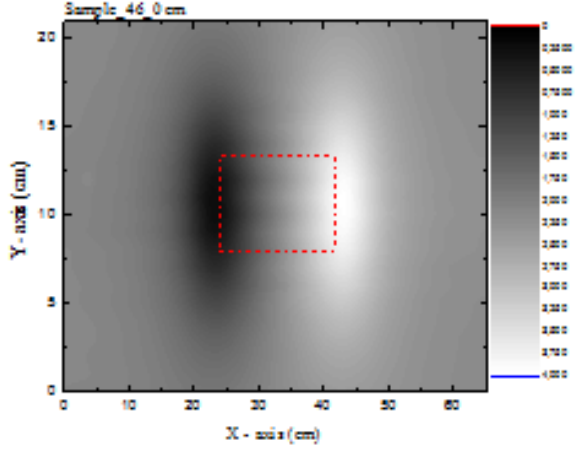

(a)

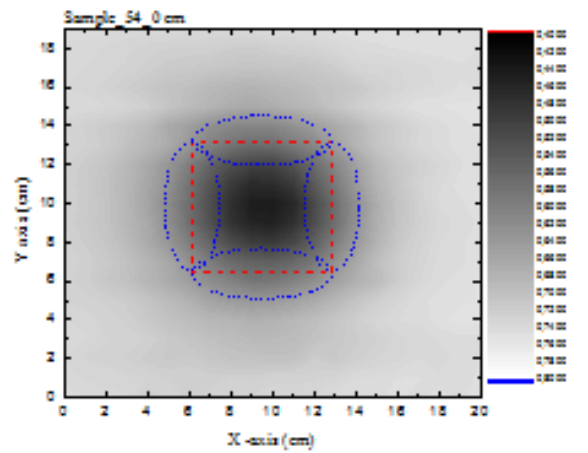

(b)

Figure 5. Sensor voltage changes of chosen prismatic samples according to the scanning field. 
Signal \& Image Processing : An International Journal (SIPIJ) Vol.7, No.5, October 2016

When Fig.5a is examined, at this big prismatic sample whose height is bigger than its width, it is understood that magnetic flux lines of the earth enter from the short edge of the sample and get out from its other short edge. When Fig.5b is examined, at this sample whose upper peaks are same, magnetic flux lines are entering into the material from all peaks.

Therefore, with the gray-scale graphs of sensor voltage changes obtained according to the sweeping field and geometric structures of the samples, it can be commented on width-height relation. In the study, in order to get height information of the prismatic samples, the change graphs of sensor output voltages are fitted according to $\mathrm{x}$ axis and the mathematical catenary that is compatible to this characteristic change is identified and the equation of this catenary is found (Fig.6).

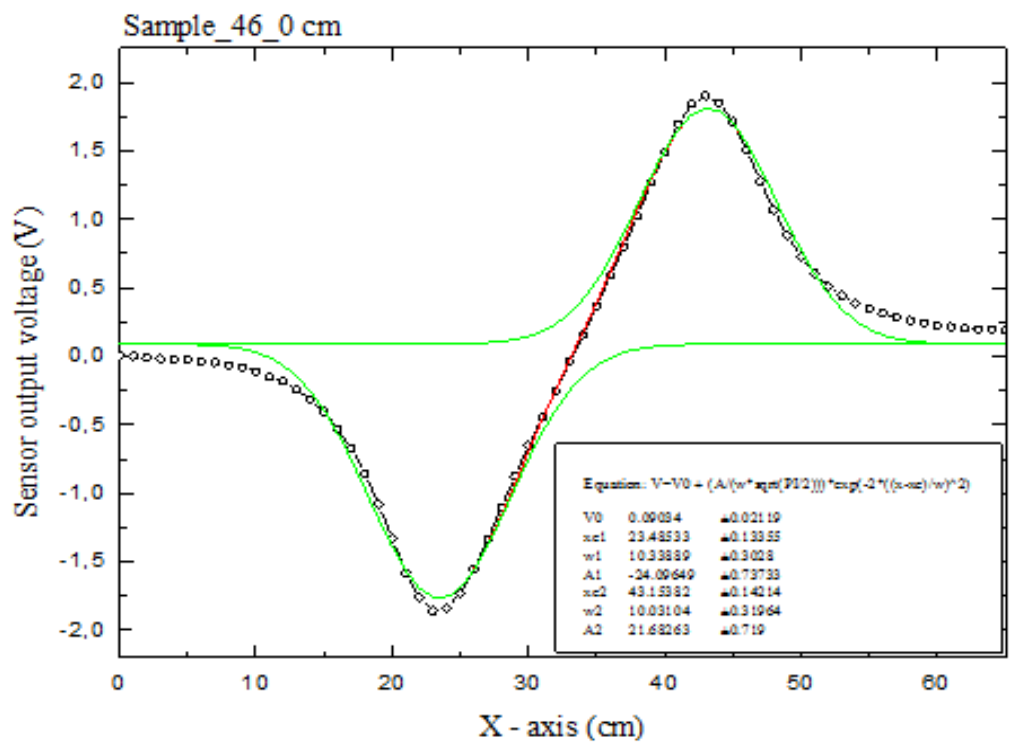

(a)

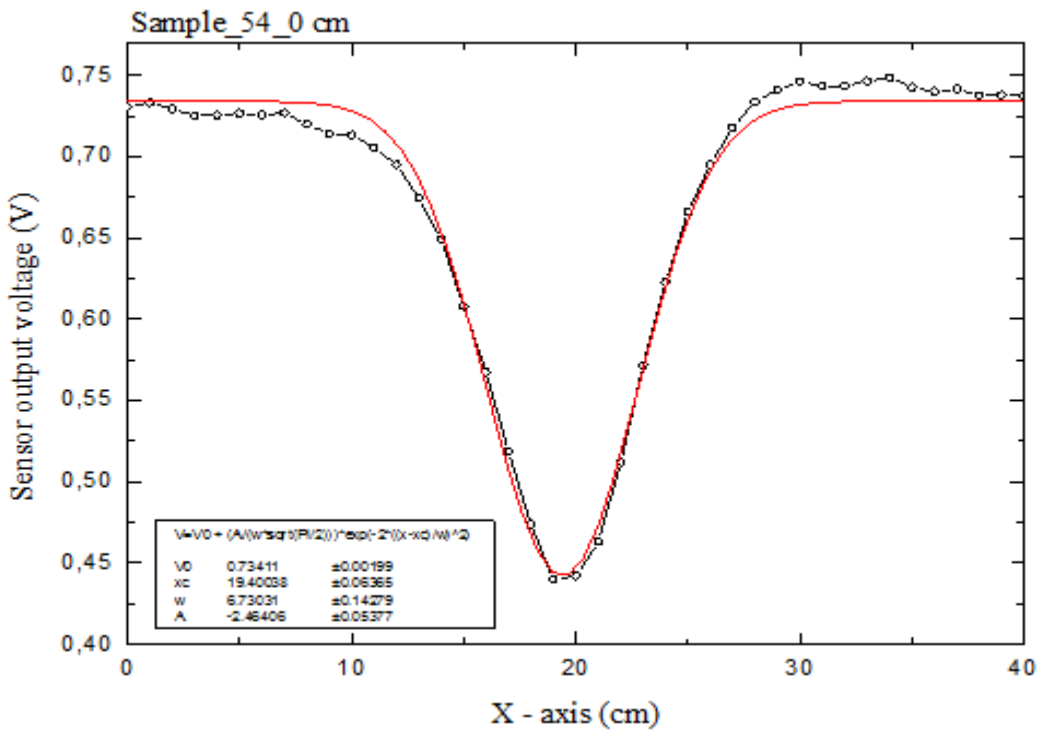

Figure 6. For prismatic samples, fitting changes of sensor output voltages according to $\mathrm{x}$ axis 
Mathematical catenary's equation that is obtained for all prismatic samples whose height are bigger than their width is as in Eq.2, on the other hand, at all prismatic samples whose height and width are same, mathematical catenary's equation is equal to Eq.3.

For prismatic samples, it is defined that $\mathrm{X}_{\mathrm{C} 1}$ and $\mathrm{X}_{\mathrm{C} 2}$ variants at mathematical catenary equation are related to the sample's height and Eq.6.

$$
\mathrm{X}_{\mathrm{C} 2}-\mathrm{X}_{\mathrm{C} 1}=-30,39+1,74 \mathrm{~L}+59,48(0,89 \mathrm{~L})^{\mathrm{L}}
$$

For identifying approximate width of prismatic samples whose heights are bigger than their widths, it will be enough to determine the distance between the ellipses on the sample's grayscale graph. When the gray-scale graphs of Sample $44(3 \mathrm{~cm})$ and Sample $47(6 \mathrm{~cm})$ which have got different width measurement are examined, it can be easily seen that the distance between two focuses of the ellipses are different and this difference approximately gives the width of the samples (Fig.7).

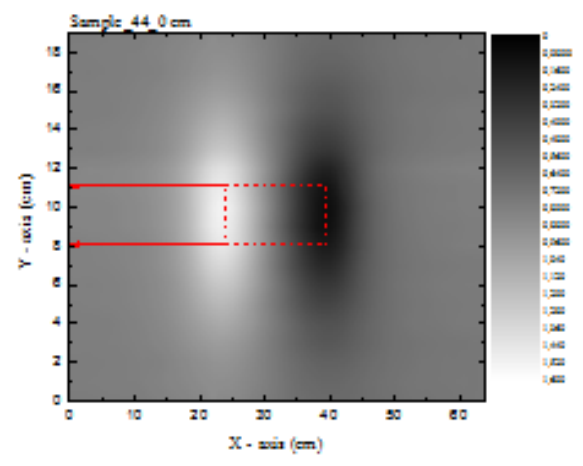

(a)

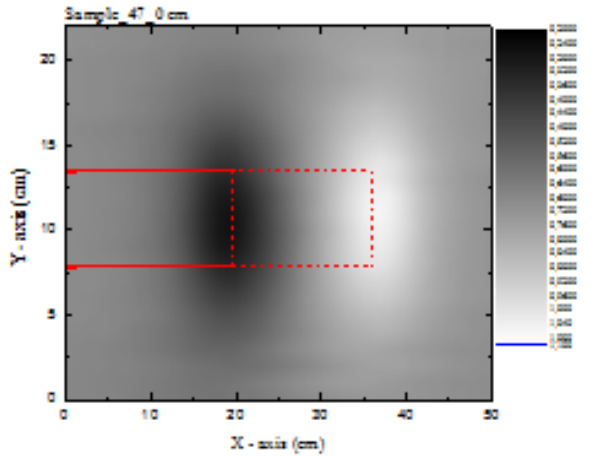

(b)

Figure 7. Two colors (gray-scale) graphs of Sample 44's and Sample 47's sensor output voltages

\section{DISCUSSION AND CONCLUSION}

In the study, a new magnetic measurement system that uses magnetic anomaly technique is developed. This system is used for determining upper surface views of buried magnetic materials, deciding whether they are standard or non-standard and classifying them. The soil that consists of $\% 4.88 \mathrm{Fe}_{2} \mathrm{O}_{3}$ is put into the soil reservoir and AISI 1030, AISI 1040 serial magnetic materials that are used in producing military metal case mines are buried into the soil with making experiments. It is found that approximate diameter information of cylindrical samples and diameter-height relation information can be obtained by determining sensor voltage changes according to the sweeping field for all selected samples, making graphs of them and determining mathematical catenary equations. In addition, it is found that prismatic samples' approximate width and height information can be determined. When magnetic permeability of the sample is high, it makes positive effect in finding geometrical features of the sample, but on the other hand, the increase of $\mathrm{Fe}_{2} \mathrm{O}_{3}$ range of the soil in which the sample is buried makes negative effect. In addition, the humidity range of the soil makes negative effect in determining geometrical features. These problems can be solved by using Boolean Kalman Filter and Maximum-Likelihood Adaptive Filtering [11-13]. Also, findings which obtained very well- known with other methods reveals that the success of our measurement system (Fig.8). 
Signal \& Image Processing : An International Journal (SIPIJ) Vol.7, No.5, October 2016

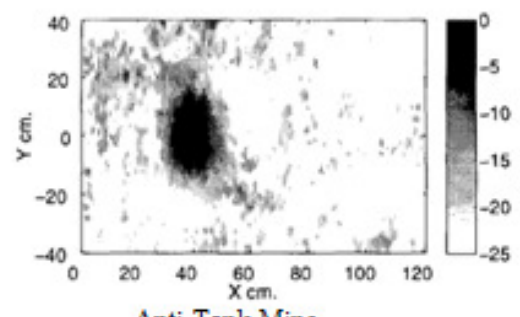

Anti-Tank Mine

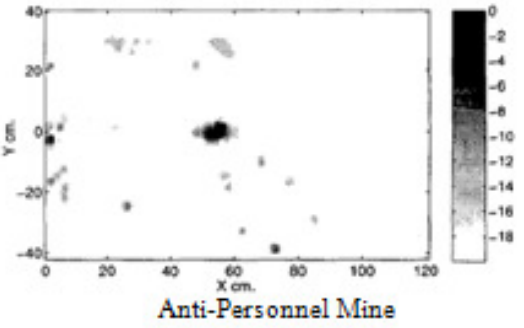

Anti-Pers onnel Mine

(a) Seismic Reflection[14]

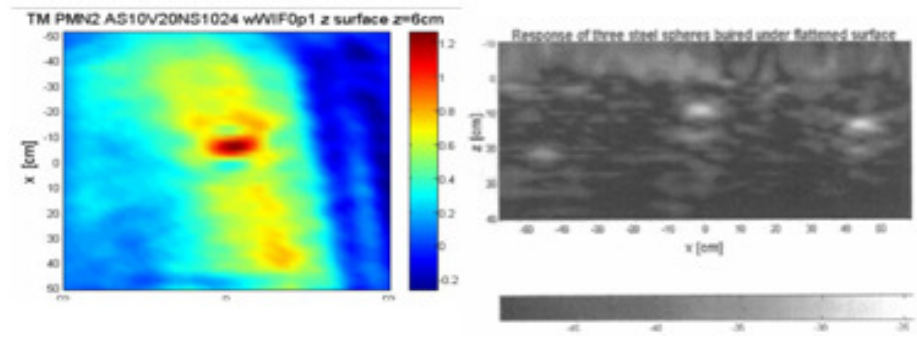

(b) Ground Penetrating Radar (GPR)[15,16]
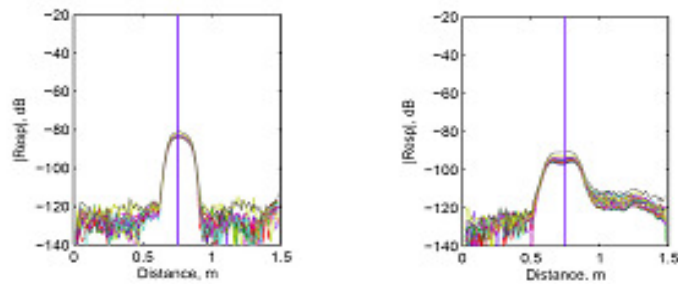

MAI-75 Mine

(c) Electromagnetic Induction (EMI)[17]
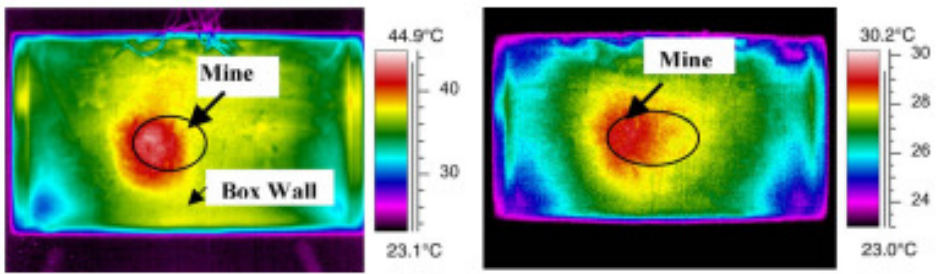

(d) Infrared Imaging (IR)[18]
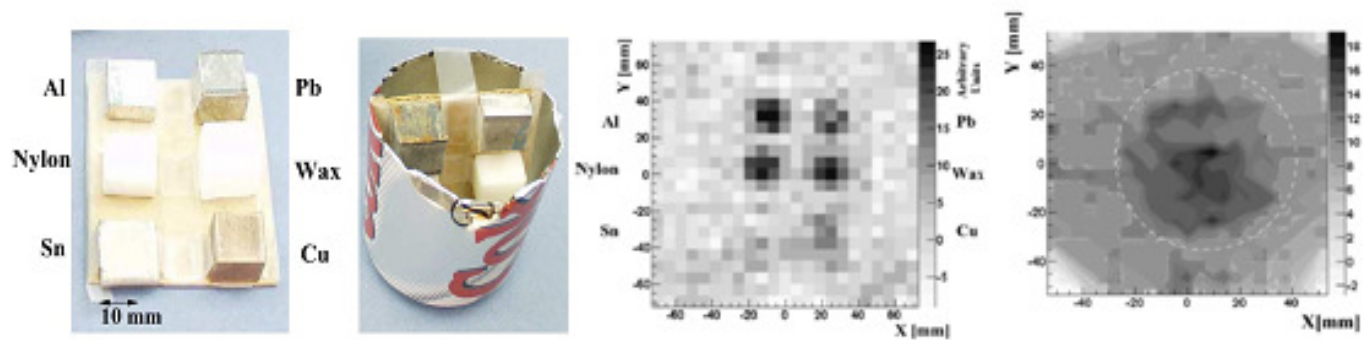

(e) X-ray Back Scattering Method[19]

PMA-2

Figure 8. Findings of other methods for the different geometric materials. 
Signal \& Image Processing : An International Journal (SIPIJ) Vol.7, No.5, October 2016

\section{REFERENCES}

[1] Sadeghi, S.H.H., Toosi, B., Moini, R., (2001). "On the suitability of induction coils for crack detection and sizing in metals by the surface magnetic field measurement technique", NDT \& E International, Vol.34, 7, pp 493-504.

[2] Kim, H., Shoji, T., (2004). "The detection of defects in paramagnetic materials using locally focused electromagnetic field technique", Advances In Nondestructive Evaluation, 270-273, pp 625- 629.

[3] Hashizume, H., Shibata, T., Yuki, K., (2004). "Crack detection method using electromagnetic waves", International Journal of Applied Electromagnetics and Mechanics, Vol.20, pp 171-178.

[4] Obeid, S., Tranjan F.M., Dogaru, T., (2007). "Eddy current testing for detecting small defects in thin films", Review of Progress in Quantitative Nondestructive Evaluation, 894, pp 340-345.

[5] Soleimani, M., (2010). "Improving the Temporal Resolution of Magnetic Induction Tomography for Molten Metal Flow Visualization”, IEEE Transactions on Instrumentation and Measurement, Vol. 59, pp 553-557.

[6] Collins, L., Gao, P., Tantum, S.,(2001). "Model-based statistical signal processing using electromagnetic induction data for landmine detection and classification", 2001 IEEE Workshop on Statistical Signal Processing Proceedings, pp 162-165.

[7] Scott, W.R., (2007). "Broadband electromagnetic induction sensor for detecting buried landmines", IEEE International Geoscience and Remote Sensing Symposium (IGARSS), Spain, 1-12, pp 22-25.

[8] Robledo, L., Carrasco, M., Mery, D., (2009). "A survey of land mine detection technology", International Journal of Remote Sensing, Vol.30, pp 2399-2410.

[9] Nazlibilek, S., Kalender, O., Ege, Y., (2011). "Mine Identification and Classification by Mobile Sensor Network Using Magnetic Anomaly", IEEE Transactions on Instrumentation And Measurement, Vol.60, pp 1028-1036.

[10] Nazlibilek, S., Ege, Y., Kalender, O., (2009). "A multi-sensor network for direction finding of moving ferromagnetic objects inside water by Magnetic Anomaly”, Measurement, Vol.42, pp 1402-1416.

[11] Imani, M., (2016)."Maximum-Likelihood Adaptive Filtering for Partially-Observed Boolean Dynamical Systems" The IEEE Transaction on Signal Processing, DOI:10.1109/TSP.2016.2614798.

[12] Imani, M., (2015)."Optimal State Estimation for Boolean Dynamical Systems using a Boolean Kalman Smoother ," in Proceedings of the 3rd IEEE Global Conference on Signal and Information Processing (GlobalSIP'2015), Orlando, FL, pp. 972-976.

[13] Imani, M., (2015)."Optimal Gene Regulatory Network Inference using the Boolean Kalman Filter and Multiple Model Adaptive Estimation ," in Proceedings of the 49th Annual Asilomar Conference on Signals, Systems, and Computers, Pacific Grove, CA, pp. 423-427.

[14] Kim, M.S., Lee, S.K., (2009), "Detection of Leak Acoustic Signal in Buried Gas Pipe Based on the Time-Frequency Analysis”, Journal Of Loss Prevention in the Process Industries, 22, pp. 990-994.

[15] Chun-Cheng, Z., Ling-Jiang, K.; Zeheng-ou, Z., (2004), "Research on Fast Synthetic Aperture Imaging Method for Ground Penetrating Radar in Subsurface Object Detection", International Conference on Communications, Circuits and Systems, Chengdu, China, June, pp. 777-779.

[16] Tanaka, R., Sato, M., (2004), “A GPR System Using A Broadband Passive Optical Sensor For Land Mine Detection", 10th International Conference On Ground Penetrating Radar, Delft, Netherlands, June, pp. 171-174. 
Signal \& Image Processing : An International Journal (SIPIJ) Vol.7, No.5, October 2016

[17] Obeid, S., Tranjan F.M., Dogaru, T., (2007), "Eddy Current Testing for Detecting Small Defects in Thin Films", Review of Progress in Quantitative Nondestructive Evaluation, 894, pp. 340-345.

[18] Brodbeck, R., Pepe, F.A., Tognina, C., Bhend, D., Zimmermann, E., Kneubühl, F.K., (1998), "Balloon-Borne Far-Infrared Fabry-Perot Spectrometer for Astrophysical Observations", Infrared Physics and Technology, 39, pp. 393-414.

[19] Cnudde, V., Cwirzen, A., Masschaele, B., Jacobs, P.J.S., (2009), "Porosity and Microstructure Characterization of Building Stones and Concretes”, Engineering Geology, 103, pp. 76- 83.

\section{AUTHORS}

Yavuz Ege received the B.S. and Ph.D. degrees from the Department of Physics, Institute of Science, Balikesir University, Balikesir, Turkey, in 1998 and 2005, respectively.

He is currently working for the Necatibey Education Faculty and Physics Education Department, Balikesir University, Balikesir. His research interests are solid physics, magnetism and power electronics.

Adnan Kakilli was born in Nevsehir, Turkey, in 1966. He received the M.Sc. and $\mathrm{Ph} . \mathrm{D}$. degrees from the Institute of Science, Marmara University, Istanbul, Turkey, in 1993 and 1999, respectively. He joined the Department of Electrical Education, Faculty of Technical Education, Marmara University, in 1989, as a Research Associate. He attended the World Bank Technical Teacher Training Project for nine months with The Ohio State University, Columbus, OH, USA, in 1994. He was promoted to a Lecturer in 1993, an Associate Professor in 1999, and an Associate Professor in 2012. He was with

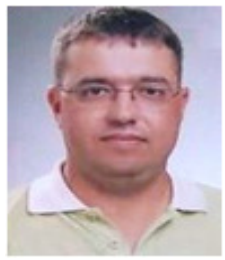
the Vocational School of Technical Sciences, Novi Sad, Serbia, since 2012, as an Associate Professor. He is currently with the Electronic and Automation Program, Vocational School of Technical Sciences, Marmara University. His current research interests include power systems, distribution networks, transmission lines, and their design.

Dr. Kakilli is a member of the Electrical Engineers Chamber of the Istanbul branch.

Hakan Çıtak received the B.S. and Ph.D. degrees from the Department of Electric Education, Institute of Science, Marmara University, Istanbul, Turkey, in 1995 and 2014, respectively.

He is currently working for the Balikesir Vocational High School, Electric Program, Balikesir University, Balikesir. His research interests are magnetism and power electronics.

Mustafa Çoramı received the B.S. degrees from the Department of Physics Education, Institute of Science, Balikesir University, Balikesir, Turkey, in 2012.

He is currently working for the Necatibey Education Faculty and Physics Education Department, Balikesir University, Balikesir. His research interests are magnetism and power electronics.
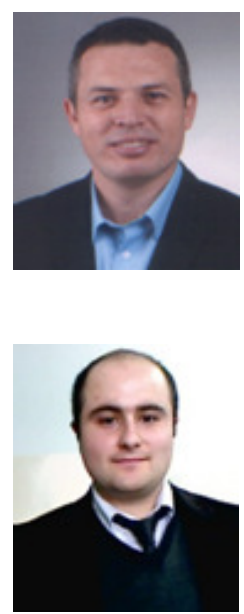